\title{
Reorganisation success in bankruptcy: the role of entrepreneur experience, characteristics and commitment
}

\section{Stefan Mayr*}

Institute of Management Control and Consulting,

Johannes Kepler University of Linz,

4020 Linz, Austria

Email: stefan.mayr@jku.at

${ }^{*}$ Corresponding author

\section{Christine Mitter}

Department of Accounting and Finance, Salzburg University of Applied Sciences, 5412 Puch/Salzburg, Austria

and

Department of Economics and Finance, University of the Free State, 9301 Bloemfontein, South Africa

Email: christine.mitter@fh-salzburg.ac.at

\section{Christine Duller}

Institute of Applied Statistics,

Johannes Kepler University of Linz, 4020 Linz, Austria

Email: christine.duller@jku.at

\section{Viktoria Mooshammer}

Institute of Management Control and Consulting,

Johannes Kepler University of Linz,

4020 Linz, Austria

Email: v.mooshammer@yahoo.de

\begin{abstract}
We examine how entrepreneur experience, characteristics and commitment impact the success of a firm's reorganisation. We refer to the resource-based view and upper echelons theory as a theoretical basis. Empirical research is based on a sample of 158 bankrupt Austrian small- and mediumsized enterprises (SMEs). To test our model, we applied bivariate analyses and logistic regression. The personality of the entrepreneur, in particular strong dynamic-creative talents, as well as concentrated ownership and financial
\end{abstract}


contributions as reflections of owners' commitment appear to be important drivers for overcoming a crisis successfully. While management and industry experience of the entrepreneur as well as education seem not to influence reorganisation success, having a reorganisation plan appears to be the most decisive factor. Our findings indicate that the entrepreneurial traits that are essential for company growth and the avoidance of failure do not impact the success of the firm's reorganisation.

Keywords: reorganisation; entrepreneur characteristics; SMEs; small- and medium-sized enterprises; financial crisis; bankruptcy.

Reference to this paper should be made as follows: Mayr, S., Mitter, C., Duller, C. and Mooshammer, V. (2021) 'Reorganisation success in bankruptcy: the role of entrepreneur experience, characteristics and commitment', Int. J. Entrepreneurial Venturing, Vol. 13, No. 5, pp.528-548.

Biographical notes: Stefan Mayr is an Associate Professor of Management Accounting and Control at Johannes Kepler University in Linz, Austria. $\mathrm{He}$ works as a business consultant in the fields of restructuring and management control.

Christine Mitter is a Professor of Management Accounting and Finance at the Business School of the University of Applied Sciences in Salzburg, Austria and a Research Fellow at the Department of Economics and Finance at the University of the Free State, Bloemfontein, South Africa.

Christine Duller is an Associate Professor of Applied Statistics at Johannes Kepler University in Linz, Austria.

Viktoria Mooshammer is a Research Partner at Johannes Kepler University in Linz, Austria.

\section{Introduction}

Small and medium-sized enterprises (SMEs) are characterised by individual leadership with entrepreneurs as the central actors (Hsieh et al., 2019). Furthermore, SMEs are important contributors to national wealth, employment, job creation (Ayyagari et al., 2007; Muller et al., 2019), and economic vitality (Carter and Van Auken, 2006). SMEs are especially critical in the European Union (EU), where they account for over $99 \%$ of all enterprises and more than two-thirds of employment in the nonfinancial business sector (Muller et al., 2019). However, bankruptcy and failure are also eminently prevalent among SMEs, particularly within their first years of operation (Carter and Van Auken, 2006; Mayr et al., 2017; Thornhill and Amit, 2003). Additionally, the current pandemic crisis is threatening the growth and survival of firms at a global scale (Lim et al., 2020; Wenzel et al., 2020).

SMEs face resource constraints, making it increasingly difficult for them to cope with and overcome crises (Geroski et al., 2010; Thornhill and Amit, 2003; Smallbone et al., 2012). Crisis management is one of the most challenging tasks in SMEs (Herbane, 2010), and entrepreneurs often deny or neglect the onset of a crisis (D'Aveni and MacMillan, 1990). Moreover, bankruptcy, as the most severe form of crisis, is disruptive, costly, and 
enormously impactful for both entrepreneurs and stakeholders such as employees, shareholders, suppliers, customers, and communities (Carter and Van Auken, 2006; Madrid-Guijarro et al., 2011; Mayr et al., 2017). Given the economic importance and vulnerability of small businesses, closer attention is needed to understand how entrepreneurs think and act in crisis situations (Herbane, 2010).

Managerial and entrepreneurial traits have been an important research focus in multiple scientific papers, and the overall results show that those characteristics impact the performance of the company (e.g., Brüderl et al., 1992; Carter and Van Auken, 2006; Schutjens and Wever, 2000). When analysing the extant literature, it becomes clear that as soon as entrepreneurial traits are taken into account, research delves into the survival of new ventures (Brüderl et al., 1992; Schutjens and Wever, 2000) and firm growth (Cooper et al., 1994; Lee and Tsang, 2001). Other studies have examined the causes of bankruptcy or financial distress (e.g., Carter and Van Auken, 2006; Madrid-Guijarro et al., 2011; Ooghe and de Prijcker, 2008; Pinkwart et al., 2015). Research on entrepreneurship and crises is also characterised by a proclivity towards studying the impact of external crises, mostly ignoring internally-induced crises (Doern et al., 2019). Only one paper-to our knowledge-specifically investigates the link between the internal causes of crises and the characteristics of the entrepreneur (Mayr et al., 2020b). However, extant literature remains relatively silent on the factors and resources that are essential for SMEs to overcome a crisis and to reorganise their firms in a successful and lasting way (Mayr et al., 2017). Moreover, since studies on financial distress emphasise large enterprises (Laitinen, 2013; Mayr et al., 2017), a so-called large company bias can be observed (Schweizer and Nienhaus, 2017). Research thus has mostly explored financial indicators that affect the ability to overcome financial crises and has rarely considered nonfinancial factors (Ooghe and de Prijcker, 2008), especially traits and resources. SMEs' resources are particularly flexible and entrepreneurial because SMEs are structured less formally than large companies and groups. In addition, the entrepreneur often directly influences the operative business (Alvarez and Busenitz, 2001; Analoui and Karami, 2003). Hence, the entrepreneur is crucial for organisational development and success (Brüderl et al., 1992). In the world of start-ups and high-risk ventures, business failure has become pervasive (Pinkwart et al., 2015). Entrepreneurs and their stakeholders therefore need to know how to overcome financial crises and reorganise their businesses. Nevertheless, despite good intentions, uncertainty remains about the influence of entrepreneurial characteristics on the outcome of a firm's reorganisation. As such, our research question is as follows: Which entrepreneurial traits and actions impact the success of a firm's reorganisation?

The aim of this study is thus twofold. First, we seek to theorise which resources and entrepreneurial characteristics are important and necessary to overcome financial crises. To do so, we embed our study in a theoretical framework consisting of two theories: the resource-based view (Barney, 1991) and upper echelons theory (Hambrick and Mason, 1984). The resource-based view points out the importance of internal strategic resources, especially for companies facing difficult situations (Thornhill and Amit, 2003), such as firm reorganisation. Upper echelons theory states that organisational outcomes reflect observable characteristics of a firm's top management (Hambrick and Mason, 1984), which refers to the entrepreneur in the context of SMEs. Drawing on these theories, we argue that the background and characteristics of the entrepreneur are important strategic resources that directly influence the success or failure of a firm's reorganisation. 
Second, we empirically test the impact of developed resources and given characteristics on the success of reorganisation. We therefore conduct an in-depth analysis of 158 Austrian SMEs out of a full sample of 459 SMEs that formally declared bankruptcy in 2012. The dataset allows the investigation of the relationship between entrepreneur-specific characteristics and entrepreneurial resources, as well as the outcomes of firm reorganisation.

The remainder of this paper is structured as follows. First, we describe the theoretical background, and this is followed by a literature review to develop the investigated hypotheses. Then we present the research methods, the data sample and the results. Based on our findings and the discussion, we outline limitations and opportunities for future research.

\section{Theoretical foundations: resource-based view and upper echelons perspective}

The resource-based view (Wernerfeldt, 1984) can be applied to both large enterprises and SMEs. However, particularly in SMEs, resources are very flexible and strongly influenced by the entrepreneur (Alvarez and Busenitz, 2001; Analoui and Karami, 2003) because SMEs are structured less formally than larger businesses. The entrepreneur has a very direct influence on the operative business, allowing for an immediate reaction to market changes (Burns, 1996). The literature contains various interpretations of the term 'resources', which can be considered not only as characteristics, traits, skills, organisational processes or tangible goods but also as information, knowledge, and intellectual property. All of these different dimensions form a company's strengths and weaknesses and together allow it to build a competitive advantage (Armstrong and Shimizu, 2007; Barney, 1991) and increase its efficiency and effectiveness (Barney, 1991).

The resource-based view was initially implemented for high-performing enterprises, but it can be applied to ailing companies as well (Thornhill and Amit, 2003) given that a firm's resources are not only substantial determinants of success but also of failure (Headd, 2003). SMEs face resource constraints and are prone to an increased failure probability due to the liability of smallness (Aldrich and Auster, 1986; Carter and Van Auken, 2006). Moreover, entrepreneurs and their businesses are tightly intertwined (Ucbasaran et al., 2013), and their access to financial and managerial resources is more limited (Geroski et al., 2010). The setbacks of a crisis can provide an opportunity for entrepreneurs to realign resources and regain balance within their entire resource system (Lim et al., 2020). From the perspective of creditors, the resource-based view provides an appropriate framework for considering the viability of failing or bankrupt SMEs (Cook et al., 2012).

From an upper echelons perspective, an organisation reflects its managers (Hambrick and Mason, 1984). Upper echelons characteristics (i.e., educational background, professional competencies, functional experiences, age, tenure in the organisation, values, attitudes, etc.) determine strategic choices and hence organisational performance. Consequently, a situation that an organisation faces at least partially reflects the entrepreneur's characteristics (Hambrick and Mason, 1984). Accordingly, the three fundamental principles underlying the upper echelons perspective are 
1 strategic decisions reveal powerful actors' values and cognitive foundations

2 observable characteristics such as education or work experience illustrate these actors' values and cognitive foundations; and, as a result

3 organisational outcomes form an association of these actors' observable characteristics (Carpenter et al., 2004).

In the context of SMEs, the entrepreneur is the central actor (Chowdhury et al., 2015) who decisively impacts an organisation. Following a broad definition of entrepreneurship elaborated by Shane and Venkataraman (2000, p.218) as "why, when, and how opportunities for the creation of goods and services come into existence", both ownermanagers and external managers of SMEs think and act in a very entrepreneurial way. Hence, in the SME context both can be defined as entrepreneurs and are investigated in the following.

In the extant literature, the main focus of upper echelons theory has been on the relationship between the entrepreneur's characteristics and the company's performance or strategic decisions, including failure and strategic renewal (Kwee et al., 2011; Mellahi and Wilkinson, 2004; Wang et al., 2016). Furthermore, previous research has found that the entrepreneur's background and education as well as professional experience are important drivers of performance and even firm survival and restart (Boden and Nucci, 2000; Brüderl et al., 1992; Madrid-Guijarro et al., 2011; Riar et al., 2021; Schutjens and Wever, 2000).

Hambrick (2007) asserted that managers who face heavy job demands, such as in a reorganisation process, will be forced to take mental shortcuts and thus have less time to contemplate their decisions. This leads them to rely on what they already know or what they have experienced in the past. Therefore, the relationship between managerial characteristics and organisational outcomes can be predicted as being stronger when the level of managerial challenges is high (Hambrick, 2007). This should apply even more so to SMEs, where all power and decisions are in the hands of the entrepreneur. For a successful long-term recovery from the crisis, the reorganisation strategy must ensure that all kinds of resources are readily available to stabilise the business and to respond to current and future customers' needs (Mayr et al., 2017). In a reorganisation, the entrepreneur has to make the right resource decisions to regain competitiveness (Mayr and Mitter, 2015). Hence, entrepreneurial personality traits are an important form of internal strategic resources, especially in demanding situations, such as in a firm reorganisation, as the entrepreneur's choices reflect his background and knowledge (Hambrick, 2007).

In this paper, the resource-based view and upper echelons theory are not competitive frameworks; they are rather complementary theories contributing to an integrated perspective of the role of the entrepreneur in firm reorganisation. On the one hand, the resource-based view mostly centres on the importance of internal strategic resources (Barney, 1991). The characteristics and skills of the entrepreneur can be classified as a form of strategic resource. On the other hand, upper echelons theory states that organisational outcomes reflect observable characteristics of the firm's top management (Hambrick and Mason, 1984), which is the entrepreneur (as the central actor) in the context of SMEs. Both theories can be integrated into a dynamic model: To the extent that management plays a role in the shaping of firm resources and consequently outcomes, firm characteristics and context (including environmental and industry 
contingencies) play a critical role in determining who serves among the firm's top leaders, as well as the nature of their impact on firm behaviours (Carpenter et al., 2004).

Bankruptcy can be defined as an in-court procedure designed to either solve the financial problems of insolvent but viable firms or to liquidate unviable distressed firms (Mayr et al., 2017). Reorganisation is consequently defined as the process of overcoming a financial crisis, either through legal procedures or outside the court system (Gilson, 1991). From a dynamic perspective it involves the readjustment, reconfiguration or extension of a firm's resources so that they fit or refit to its environment's needs (again) and ranges from downsizing over the readjustment of existing structures to renewal, development and growth as the 'highest level' (Helfat and Peteraf, 2003; Mayr and Mitter, 2015). Reorganisation comprises of a wide array of actions such as operational and strategic measures as well as retrenchment and recovery actions (Schweizer and Nienhaus, 2017; Trahms et al., 2013). Moreover, there are various nuances in defining reorganisation success ranging from sharp-bend recovery, moderate recovery to mere survival of the reorganisation process in contrast to liquidation (Succurro, 2012; Trahms et al., 2013). In the following, we rely on this latter definition and consider the reorganisation of a bankrupt company successful if the company is still running after acceptance of the reorganisation plan or if it is taken over by a rescue company. The empirical evidence of the effect of these actions on firm performance is inconclusive, indicating to several contingencies that may impact reorganisation success (Schweizer and Nienhaus, 2017; Trahms et al., 2013). One such contingency is the entrepreneur who can impede or facilitate the reorganisation (Trahms et al., 2013). His or her ability to meet the firm's and environment's requirements in the reorganisation process is decisive for the outcome of the process (Chen and Hambrick, 2012). The entrepreneur is the crucial player to unleash a company's potential and to turn the pressure related to crisis in something positive (Mayr and Mitter, 2015). Hence, the success of a reorganisation is closely linked to the entrepreneur's ability to react in a timely manner to a crisis, to stimulate radical changes, and to harness the company's resources (Cucculelli and Peruzzi, 2020; Mayr and Mitter, 2015).

\section{Previous research and development of the hypotheses}

\subsection{Overview}

The existing literature on the influence of the entrepreneur on firm success provides very heterogeneous results because studies have placed different emphases on the investigated variables (Schutjens and Wever, 2000). The same applies to literature on the influence of the entrepreneur and his or her characteristics on the management of a financial crisis. Some researchers have concentrated on the causes of bankruptcy, others have examined overcoming bankruptcy or crises in general, and others have focused on firm survival and reorganisation after bankruptcy. The role of the entrepreneur as well as the factors and resources that are imperative to overcome a crisis and promote a successful reorganisation have rarely been analysed (Mayr et al., 2017; Trahms et al., 2013).

Success and failure have traditionally been linked to the entrepreneur's traits and background (Schutjens and Wever, 2000). From an upper echelons perspective, the characteristics of the entrepreneur (i.e., his or her experience, personality type or education) determine his or her strategic choices and hence organisational performance 
(Hambrick and Mason, 1984) in both economically good times and in distressed situations (such as a reorganisation). Studies that have investigated failed firms have commonly focused on the causes of business failure (e.g., Carter and van Auken, 2006; Mayr et al., 2020b; Michael and Combs, 2008; Ooghe and de Prijcker, 2008) and concluded that the presence of certain entrepreneurial characteristics decreases or increases the likelihood of failure. These characteristics include the impact of age, gender, education, and management and industry experience, which have been explored with varying results (Laitinen, 2013; Lussier and Corman, 1996; Mayr et al., 2020b).

\subsection{Experience of the entrepreneur}

Having previous work experience in a specific sector before attempting to set up one's own business is vital for a firm's success (Schutjens and Wever, 2000). This is explicitly supported by the findings of Brüderl et al. (1992), who advised that the best preparation for a future founder is to gain experience in the industry, perhaps in a small company in which the whole array of requirements can be seen. Their research focused on the chances of survival for newly founded businesses, and they argue that greater human capital increases the productivity of the entrepreneur, which leads to higher profits. Their results show that founders with industry-specific or leadership experience are less likely to fail.

Likewise, Carter and van Auken (2006) found that owners with little industrial experience and training are more likely to fail. In addition, Lee and Tsang (2001) confirmed that an entrepreneur's industry and managerial experience have a great effect on the venture growth of SMEs. Pinkwart et al. (2015) investigated the reasons for the failure of new technology-based firms and cited management variables, i.e., the abilities of the entrepreneur, as one significant explanatory factor of failure. Additionally, Bates (1990) noted that education is the strongest human capital variable for the business continuance of newly founded firms. Arguably, the owner's educational background is a major determinant of the level of financial capital invested in small business start-ups. Moreover, Cooper et al. (1994) compiled evidence that the probability of marginal survival and growth increases with the level of education and industry experience. Mayr et al. (2020b) provided evidence that management experience reduces the risk of failure due to certain internal causes. Concretely, managerial experience reduces the risk of bankruptcy due to poor business economic competencies and high-cost pressure.

However, the empirical results are not entirely clear and also show contrary findings. For example, although Cooper et al. (1994) found industry experience to be an important variable influencing survival and growth, their results do not support the assumption that management experience is as well. Similarly, Madrid-Guijarro et al. (2011) investigated the relationships between the manager's education, his or her level of professional experience and financial distress and did not find empirical support for their assumptions of a negative relationship.

In summary, however, a large number of prior findings confirm the positive correlation between management and industry experience as well as education, especially at the university level, on growth, success, and avoidance of failure. In addition, a lack of management experience and knowledge is one of the main reasons for financial crises. Since the entrepreneur is the decisive actor in the turnaround actions of a firm, we assume 
that gained experience will also positively influence the success of a reorganisation. Based on these arguments, we derive the following hypotheses:

\section{H1: Industry experience positively influences successful reorganisation.}

H2: Management experience positively influences successful reorganisation.

H3: A university degree positively influences successful reorganisation.

\subsection{Type of entrepreneur (entrepreneur characteristics)}

The success of enterprises is often related to the involvement of a certain type of entrepreneur, and psychological models are therefore used to differentiate the various types of entrepreneurs (Bögenhold et al., 2014; Schutjens and Wever, 2000). Research on personality aspects of entrepreneurship has intensified during the last two decades. Nevertheless, psychological models and concepts or personality traits of entrepreneurs are blurred (Brandstätter, 2011). Based on that one may conceptualise personality traits as complex, genetically co-determined psycho-physiological structures.

For this paper we draw on a value and attitude driven model of entrepreneurship, that was designed in the context of SMEs: The European research group Strategic Orientation of Small and Medium-sized Enterprises (STRATOS) investigated how the capabilities of entrepreneurs affect SME firm performance and success (Fröhlich and Pichler, 1988), and they identified four different types of entrepreneurs. The researchers argued that certain capabilities and attitudes can be classified under entrepreneur types. Characteristics such as the willingness to take risks, level of responsibility, and personal commitment constitute prerequisites. To assign entrepreneurs to types, they focused on two main attitudinal spheres: the dynamic-creative sphere and the administrative-executive sphere (Fröhlich and Pichler, 1988). The advantage and justification of the model can be seen in the practicable allocation of entrepreneurs to the individual types. With the help of observable characteristics (e.g., creativity or organisational talent) and perceived tasks (e.g., assumption of administrative and routine activities), a typification is comparatively simple. Table 1 displays the classification of entrepreneur types according to a combination of talents.

Table 1 Classification of entrepreneur types according to a combination of talents

\begin{tabular}{lcl}
\hline Dynamic-creative & Administrative-executive & Type of entrepreneur \\
\hline strong $(+)$ & strong $(+)$ & Allrounder \\
strong $(+)$ & weak $(-)$ & Pioneer \\
weak $(-)$ & strong $(+)$ & Organiser \\
weak $(-$ & weak $(-)$ & Routineer \\
\hline
\end{tabular}

The first type identified is the Allrounder, portraying strengths in both spheres with various talents. In the case of SMEs, Allrounders are their own designers, salespeople, and administrators. However, Fröhlich and Pichler (1988) stated that this role variation necessarily leads to mediocrity. The second type, the Pioneer, possesses strong traits in the dynamic-creative sphere and can be described as a creative and innovative person. The Organiser, whose strengths lie in the administrative-executive sphere, can be defined as a rational and analytical person who has a talent for supreme organisation. The last 
type, the Routineer, does not exhibit specific strengths in either sphere. His or her capability for running a business lies in showing one or more of the prerequisites stated above. The Routineer can be labelled the classical risk carrier, constituting the counterpart of the Pioneer (Fröhlich and Pichler, 1988). Fröhlich and Pichler (1988) assumed that the Routineer has a very low probability of firm success and an increased chance of failure due to his or her lack of abilities in both the dynamic-creative and administrative-executive spheres. They even associated their entrepreneur types with the four types of temperament theory and equated the Routineer with the Phlegmatic, who is not a good entrepreneur (Fröhlich and Pichler, 1988).

Given that entrepreneurial activity in the context of a crisis is not so much 'business as usual', as it is 'uncommon' and 'unusual', necessitating a different approach towards doing business (Doern et al., 2019), it becomes clear that different types of entrepreneurs also react differently to such a challenge. In a reorganisation, the entrepreneur needs to stimulate radical changes and realign the resources of the company (Mayr and Mitter, 2015). This requires both creative skills in envisioning this change and administrative strengths in organisational implementation.

Based on these arguments, we derive the following hypothesis:

H4: The entrepreneur types of Allrounder, Pioneer, and Organiser have a significantly higher chance of successful reorganisation than the Routineer type.

\subsection{Planning}

Headd (2003) found that a firm's resources impact performance, with strategic planning being one decisive strategic resource. Research has identified correlative evidence that suggests that the amount of strategic planning can reduce the risk of financial distress and failure (Laitinen, 2013; Madrid-Guijarro et al., 2011; Perry, 2001). A study by Perry (2001) focused on the relationship between written business plans and the failure of small businesses. In this study, non-failed firms focused more precisely on planning than did similar firms prior to their failure. Perry (2001, p.204) summarised the results as follows: "small business managers tend to be either planners or non-planners, with few occupying the middle ground". Lussier and Corman (1996), who developed a success vs. failure prediction model, concluded that entrepreneurs who started their firm with a specific business plan had a greater chance of success than those who did not.

Reorganising a firm in distress requires the reconfiguration and orchestration of resources, thereby balancing and synchronising measures such as divestments and rebundling or retrenchment and recovery actions (Trahms et al., 2013). Planning can support this process as it anticipates the effects of reorganisation measures and helps synchronise various actions. Moreover, having a business plan and experience in operational planning is a precondition for the preparation and presentation of reorganisation plans. Furthermore, Laitinen (2013) linked strategic business planning to the reorganisation plan as a form of strategic planning once a firm is in a crisis. He found that reorganisational planning plays a central role in minimising the risk of failure in small business reorganisation (Laitinen, 2013). The reorganisation plan therefore plays a central role in restructuring in general and in bankruptcy in particular. The reorganisation plan contains both operational and strategic considerations regarding the insolvent company's future, and is subsequently used for communicating with stakeholders/ creditors during the reorganisation (D'Aveni and MacMillan, 1990). A convincing 
concept makes it more likely that creditors will be willing to vote for the plan (Gilson, 2012). Hence, we hypothesise:

\section{H5: A reorganisation plan positively influences successful reorganisation.}

\subsection{Entrepreneurial discretion and commitment}

Further factors that may affect the likelihood of successful reorganisation are related to concentrated ownership and (financial) owner contribution. Previous research framed by upper echelons theory has pointed to equity ownership as an aspect of "managerial discretion". This managerial responsibility increases the influence of an entrepreneur's characteristics on his or her decision making (Haas and Speckbacher, 2017). Even though less concentrated ownership can lead to a more objective reaction to financial distress (Keasey et al., 2015), concentrated ownership is an indicator of the owner's connection and relationship with his or her company. Chitnomrath et al. (2011) proved that concentrated ownership is positively associated with post-bankruptcy performance.

Given that illiquidity is a bankruptcy trigger in various insolvency regimes, safeguarding or restoring liquidity is a central reorganisation measure. One such action to improve liquidity are equity infusions by the existing owners (Schweizer and Nienhaus, 2017) but their financial contributions can occur in other forms as well such as the provision of guarantees, or third-party collateral to enable additional bank financing. This additional funding access may be vital for survival as it enables on the one hand the continuation of the distressed firm's day-to-day operations and on the other hand the financing of strategic turnaround actions (Trahms et al., 2013). In accordance with the findings of Mayr et al. (2020a), for out-of-court settlements, we also expect a positive influence of the owner's financial contributions on the success of court-supervised legal reorganisation. As such, concentrated ownership and financial contributions from the owner are expected to positively affect the outcome of firm reorganisation. Therefore, we postulate the following:

H6: Concentrated ownership positively influences successful reorganisation.

H7: Financial contributions from the owner positively influence successful reorganisation.

\subsection{Contingency factors}

Additionally, a review of the literature reveals that firm age influences the level of business success or failure (Kücher et al., 2020). This is linked to the liability of newness, and new ventures are more likely to fail than more established ones (e.g., Aldrich and Auster, 1986; Bates, 1990; Carter and van Auken, 2006; Headd, 2003; Mayr et al., 2017; Ooghje and de Prijcker, 2008; Thornhill and Amit, 2003). Thornhill and Amit (2003) found, for example, that young firms are at risk because of their lack of valuable resources and capabilities. Bates (1990) also stated that very young firms are less likely to survive than older firms. Mayr et al. (2017) showed that younger and smaller firms are more prone to distress since they are less diversified, and therefore cannot profit from scale effects and have a smaller risk buffer. Firm-specific characteristics, such as firm age, are expected to affect the sustainable reorganisation of SMEs. However, Carter and van Auken (2006), who investigated whether the liability of newness causes bankruptcy, 
did not find support for this assumption.

Previous evidence has also identified industry effects on the success of reorganisation. The industry in which a company operates reflects its business circumstances to a large extent and may affect success or failure in firm reorganisation. Some industries are more complex than others and this complexity may be connected with the difficulty or ease of reorganisation (Laitinen, 2013). Consequently, industry seems to influence a sustainable reorganisation (Mayr et al., 2017). Since both firm age and industry have been found to have an influence on successful reorganisation, they are added to our model as moderating variables.

\section{Empirical research}

\subsection{Study design and sample description}

Empirical research is based on a sample of all bankrupt SMEs in the Austrian Federal State 'Upper Austria' in 2012. Data were collected between January 2015 and May 2016 as part of a larger research project by analysing the bankruptcy files of a credit reference company ("Alpenländischer Kreditorenverband"). To assure plausibility each data record was collected considering the four-eyes principle. We added information from the Austrian commercial register and also gained additional insights from the two experts of the credit reference company who assisted us in collecting the data. The sample is representative of Austrian insolvencies, as it reflects the population of Austrian insolvencies according to various parameters (for similar approaches, see Laitinen, 2013; Mayr et al., 2017).

The full Upper Austrian sample consists of 459 insolvencies. Due to the limited availability of detailed information, this empirical research was based on companies that were undergoing a reorganisation process or that were bankrupt SMEs with ten and more employees, resulting in a sample of 158 enterprises. For all 158 companies, specific entrepreneurial traits were surveyed.

\subsection{Variables and statistical methodology}

After carrying out some bivariate tests for the hypotheses proposed in Section three, we built a logistic regression model to obtain better insight into the multivariate dependencies. One interesting outcome of the regression model (= dependent variable) was the successful reorganisation of a formal bankrupt SME, whereas a firm was considered to be successfully reorganised if the company was still operating at the time of examination or if it had been taken over by a rescue company. We analyse SMEs according to the definition of the European Union up to 249 employees.

The explaining variables of the model (= independent variables) are the personality traits of the entrepreneur as well as the entrepreneurial actions and the ownership structure defined in the hypotheses in Section three, most of which were recorded as dichotomous variables. To measure industry experience, management experience, and university degree, we distinguished the entrepreneurs based on whether they had a certain trait or not (the reference category in the regression model). Entrepreneur type is the only nondichotomous independent variable. Based on the assessment of the two experts of the credit reference company, the entrepreneurs were categorised into four types, as 
introduced in Section 3.3. We classified each entrepreneur as an Allrounder, a Pioneer, an Organiser, or a Routineer; the Routineer served as the reference class in the regression model. The variables for having a reorganisation plan, concentrated ownership and financial contributions from the owner were dichotomous (yes/no), with 'no' as the reference category.

Two control variables were included in the regression model: 'Age of the firm' was taken into account as a metric variable. We classified industry (under the categories of 'service', 'construction/building', 'trade', 'manufacturing', and 'other') as a categorial variable, using 'other' as a reference class.

First, bivariate analyses were conducted to investigate whether the respective variable influences successful reorganisation. For the dichotomous variables, we performed Fisher's exact test (one-sided) and carried out the exact Fisher-Freeman-Halton test for the entrepreneur type and the four categories. In the second step, we examined the model via logistic regression. The logistic regression analysed to what extent multiple variables together influenced one targeted variable; we applied it as a data reduction method that scrutinises the dependency of one variable of interest (successful reorganisation) on multiple independent variables.

\section{Results}

\subsection{Descriptives and bivariate analyses}

Before taking a deeper look at the investigated variables, Table 2 reviews some descriptive data of the sample of 158 insolvencies.

Successful reorganisation was possible in $39 \%$ of the sample cases, so the majority of reorganisations were not successful.

Concerning personal traits, the strong lack of management experience was especially interesting ( $71 \%$ had no experience, $29 \%$ had experience); in contrast, $76 \%$ of the entrepreneurs had industry experience. The vast majority had no university degree $(92 \%)$, and the entrepreneur types were almost equally distributed with the exception of the Routineer, who covered $35 \%$ of all cases. Most of the companies had concentrated ownership (87\%) and did not have a reorganisation plan (75\%). The situation concerning financial contributions was more or less balanced, and $56 \%$ had no contribution from the owner. Table 2 also displays the main industries in which the companies of the sample operated. The largest sector was service, with almost $50 \%$ of all sample firms, followed by construction/building, with approximately $30 \%$. Trade and manufacturing represented $12 \%$ and $7 \%$, respectively. We did not classify approximately $4 \%$ of the companies under a specific sector.

Table 3 shows the bivariate results of Fisher's exact test and the Fisher-FreemanHalton test. For all binary variables, we used the one-sided p-values of Fisher's exact test. For entrepreneur type, we calculated the p-value of the Fisher-Freeman-Halton test. The bivariate tests clearly indicate the significance of having a reorganisation plan with a p-value of 0.000 , as well as of the financial contributions of the owner. Additionally, the bivariate results suggest that the entrepreneur's personality traits are not as important as managerial resources. 
Table 2 Descriptives

\begin{tabular}{|c|c|c|c|c|}
\hline Dependent variables & Categories & Cases & Percentage & Valid cases \\
\hline \multirow[t]{2}{*}{ Successful reorganisation } & No & 97 & $61 \%$ & 158 \\
\hline & Yes & 61 & $39 \%$ & \\
\hline \multicolumn{5}{|l|}{ Independent variables } \\
\hline \multirow[t]{2}{*}{ Industry experience } & No (r.c.) & 38 & $24 \%$ & 158 \\
\hline & Yes & 120 & $76 \%$ & \\
\hline \multirow[t]{2}{*}{ Management experience } & No (r.c.) & 111 & $71 \%$ & 157 \\
\hline & Yes & 46 & $29 \%$ & \\
\hline \multirow[t]{2}{*}{ University degree } & No (r.c.) & 145 & $92 \%$ & 158 \\
\hline & Yes & 13 & $8 \%$ & \\
\hline \multirow[t]{4}{*}{ Entrepreneur type } & Allrounder & 37 & $23 \%$ & 158 \\
\hline & Organiser & 33 & $21 \%$ & \\
\hline & Pioneer & 33 & $21 \%$ & \\
\hline & Routineer (r.c.) & 55 & $35 \%$ & \\
\hline \multirow[t]{2}{*}{ Reorganisation plan } & No (r.c.) & 119 & $75 \%$ & 158 \\
\hline & Yes & 39 & $25 \%$ & \\
\hline \multirow[t]{2}{*}{ Concentrated ownership } & No (r.c.) & 21 & $13 \%$ & 158 \\
\hline & Yes & 137 & $87 \%$ & \\
\hline \multirow{2}{*}{$\begin{array}{l}\text { Financial contributions of } \\
\text { owner }\end{array}$} & No (r.c.) & 88 & $56 \%$ & 158 \\
\hline & Yes & 70 & $44 \%$ & \\
\hline \multicolumn{5}{|l|}{ Control variables } \\
\hline \multirow[t]{5}{*}{ Industry } & Service & 76 & $48 \%$ & 158 \\
\hline & Construction/building & 45 & $28 \%$ & \\
\hline & Trade & 19 & $12 \%$ & \\
\hline & Manufacturing & 11 & $7 \%$ & \\
\hline & Other (r.c.) & 7 & $4 \%$ & \\
\hline Age (years) & Minimum Maximum & Mean & Median & STD \\
\hline & 403 & 22.04 & 9.0 & 41.06 \\
\hline Additional Information & & & & \\
\hline Number of employees & Minimum Maximum & Mean & Median & STD \\
\hline & 143 & 23.18 & 15.00 & 25.00 \\
\hline
\end{tabular}

r.c. $=$ reference category in regression model, $\mathrm{STD}=$ Standard deviation.

\subsection{Multivariate analysis - logistic regression}

Bivariate results can give an initial hint, but what are the important explanatory variables from a multivariate angle? To obtain deeper insight, Table 4 presents the results of the stepwise logistic regression for the second step. 
Table 3 Descriptive results from the bivariate analyses

\begin{tabular}{lccc}
\hline Hypothesis & Expected influence & p-value & Result \\
\hline H1: Industry experience & $\uparrow$ & 0.054 & $*$ \\
H2: Management experience & $\uparrow$ & 0.491 & n.s \\
H3: University degree & $\uparrow$ & 0.188 & n.s \\
H4: Entrepreneur type & $\uparrow \downarrow$ & 0.063 & $*$ \\
\hline H5: Reorganisation plan & $\uparrow$ & 0.000 & $* * *$ \\
H6: Concentrated ownership & $\uparrow$ & 0.103 & n.s \\
H7: Financial contribution of owner & $\uparrow$ & 0.000 & $* * *$ \\
\hline
\end{tabular}

$* p<0.1, * * p<0.05, * * * p<0.01$, n.s. $=$ not significant.

Table 4 The results of logistic regression

\begin{tabular}{|c|c|c|c|c|c|c|c|}
\hline \multirow[b]{2}{*}{ Variables } & \multirow{2}{*}{$\frac{\text { Reference }}{\text { class }}$} & \multicolumn{3}{|c|}{ Full model } & \multicolumn{3}{|c|}{ Final model } \\
\hline & & $\exp (b)$ & \multicolumn{2}{|c|}{$p$ value } & $\exp (b)$ & \multicolumn{2}{|c|}{$p$ value } \\
\hline Industry experience & no & 1.414 & 0.508 & & & & \\
\hline Management experience & no & 0.415 & 0.073 & $*$ & & & \\
\hline University degree & no & 3.075 & 0.161 & & & & \\
\hline Entrepreneur type & Routineer & & 0.082 & $*$ & & 0.062 & $*$ \\
\hline Allrounder & & 3.945 & 0.012 & $* *$ & 3.714 & 0.013 & $* *$ \\
\hline Organiser & & 1.737 & 0.355 & & 1.694 & 0.359 & \\
\hline Pioneer & & 2.581 & 0.115 & & 2.970 & 0.049 & $* *$ \\
\hline Reorganisation plan & no & 8.374 & 0.000 & $* * *$ & 6.038 & 0.000 & $* * *$ \\
\hline Concentrated ownership & no & 4.799 & 0.041 & $* *$ & 3.254 & 0.066 & $*$ \\
\hline Financial contribution & no & 2.185 & 0.068 & $*$ & 2.394 & 0.026 & $* *$ \\
\hline Age & & 0.994 & 0.411 & & & & \\
\hline Industry & other & & 0.833 & & & & \\
\hline service & & 2.068 & 0.467 & & & & \\
\hline construction/building & & 1.486 & 0.700 & & & & \\
\hline trade & & 2.777 & 0.370 & & & & \\
\hline manufacturing & & 1.302 & 0.849 & & & & \\
\hline Constant & & 0.017 & 0.003 & $* * *$ & 0.045 & 0.000 & $* * *$ \\
\hline \multicolumn{8}{|l|}{ Model fit } \\
\hline Cox \& Snell Pseudo- $R^{2}$ & & \multicolumn{2}{|c|}{0.256} & & \multicolumn{2}{|c|}{0.226} & \\
\hline Nagelkerke's Pseudo- $R^{2}$ & & \multicolumn{2}{|c|}{0.348} & & \multicolumn{2}{|c|}{0.307} & \\
\hline
\end{tabular}

Levels of significance: ${ }^{*} p<0.10 ; * * p<0.05 ; * * * p<0.01$.

The full model includes all independent variables as well as the control variables, and the final model variables cover significant results (level 0.1) exclusively. For each model, the odds ratios of the regression coefficients $(\exp (b))$ and the p-values are shown. Holding a 
university degree, having previous industry experience, and having management experience had no significant influence on successful reorganisation, and the control variables age and industry were not significant.

When analysing the statistically significant variables, the results show that entrepreneur type, having a reorganisation plan, concentrated ownership, and financial contributions are the most important variables for successful reorganisation. Our findings indicate that the assumption of Fröhlich and Pichler (1998), whereby the Routineer is less likely to survive and hence less likely to successfully reorganise his or her company, is supported. The results show that while the Allrounder and Pioneer types have a significantly higher chance of successful reorganisation, the Organiser does not. The Allrounder had the highest odds ratio of successful reorganisation compared to the Routineer by 3.71 times, followed by the Pioneer by 2.97 times. Since hypothesis four stated that the Allrounder, Pioneer, and Organiser entrepreneur types have a significantly higher chance of successful reorganisation than the Routineer type, H4 is partially supported.

The variable that affects successful reorganisation the most is having a reorganisation plan. Enterprises with a reorganisation plan have a six times higher chance of successfully reorganising. This finding stresses the importance of the entrepreneur's strategic planning and communication abilities (Perry, 2001). Additionally, other managerial aspects, such as concentrated ownership and financial contributions, influence the success of reorganisation; the former is significant only at the 0.1 level, indicating a three times higher chance of successful reorganisation, while the latter is significant at the 0.05 level, revealing a two times higher chance of success.

\section{Discussion and conclusion}

Success or failure is traditionally linked with entrepreneurial traits and the entrepreneur's educational background (Schutjens and Wever, 2000). In this paper, we focused on the success of reorganisations and analysed the role of the entrepreneur in reorganisation success. We grouped these entrepreneurial influencing factors and analysed their impact on the success of reorganisation.

Previous findings indicate that experience gained in the past has a positive effect on companies' economic success and their growth rate (Schutjens and Wever, 2000; Brüderl et al., 1992; Lee and Tsang, 2001). While management experience appears to be crucial when it comes to the avoidance of failure (Mayr et al., 2020b), this clearly does not hold for the success of reorganisation in bankruptcy. In our logistic regression, industry experience, management experience, and university degree did not have a significant, positive influence on the success of reorganisation. While industry experience was relatively common in our sample $(76 \%)$, the investigated entrepreneurs had significantly less prior management experience $(29 \%)$ and were less likely to have a university degree $(8 \%)$. The study therefore provides new findings that entrepreneurial experience is of varying importance in the lifecycle of a company: While it is of great importance for development, growth and the avoidance of failure, other entrepreneurial characteristics are apparently more crucial in reorganisation. This finding thus provides completely new insights into the life cycle-oriented meaning of entrepreneurial experience. A possible explanation might be that (management) experience per se does not mean that one has experience in mastering crises. Obviously, the entrepreneurs of the investigated firms 
were not able to profit from this general experience in the crisis. This implies that a completely different managerial skill set is necessary in reorganisation. Moreover, experience may also result in counterproductive effects if one is not open to new ideas and concepts but acts according to the motto "we have always done it this way, we will continue to do it this way".

Our findings indicate that the entrepreneurial traits that are essential for company growth and the avoidance of failure, do not impact the success of the firm's reorganisation. In other words, the ability to assess the development of the industry or to manage a company appears to be a basic requirement that must be supplemented by other factors in the reorganisation process. The results of the logistic regression analysis indicate that inherent personal characteristics of the entrepreneur have a deep influence on the success of reorganisation. Referring to the model by Fröhlich and Pichler, our findings show that the Organiser, with his or her exclusively administrative skills, has a scarcely higher chance of rehabilitation success than the Routineer, who, according to the model, has no specific talents. The Pioneer (strong dynamic-creative talents) and the Allrounder (strong dynamic-creative and administrative-executive talents) have a significantly greater chance of a positive outcome of reorganisation. This evidently means that dynamic-creative skills are particularly in demand in reorganisation. The results confirm prior findings that characteristics related to entrepreneurial orientation such as risk-taking, opportunity-seeking, innovativeness, forward-looking perspective, and autonomy are crucial to overcoming crises and thus for successful reorganisation (Mayr and Mitter, 2015).

In accordance with previous studies (Laitinen, 2013; Perry, 2001), our model confirmed the strong influence of a plan (or the ability to devise one) on a company's success. Given that having a reorganisation plan appears to be the most decisive factor for a successful reorganisation in our logistic regression, creditors' confidence in the success of reorganisation can only be increased by creating and presenting a plan. Reorganisation is possible in bankruptcy only when creditors approve the plan (Gilson, 2012). The reorganisation plan thus fulfils two tasks: On the one hand, it serves as a confidence-building measure for creditors, whose approval becomes more likely. The preparation and submission of a plan proves that the entrepreneur has reflected on the company's situation and learned from the mistakes that led to failure and is fully committed to the turnaround. On the other hand, the plan facilitates reorganisation. As a more structured approach is taken, deviations from the plan and unfavourable developments are recognised more quickly, and the success of implementing the measures is thus also ensured. In terms of court-supervised reorganisation, our results also corroborate the findings of prior research regarding the importance of communicating with creditors in out-of-court restructuring (Mayr et al., 2020a).

With regard to entrepreneurial discretion and commitment, we found evidence that, as expected, both concentrated ownership and financial contributions from the owner are very important elements of successful reorganisation. The results therefore confirm those of Chitnomrath et al. (2011), whereby concentrated ownership has a positive effect on the success of reorganisation due to owners' high level of commitment to their own company. Concentrated ownership may also reflect a high level of autonomy and flexibility of the entrepreneur in decision-making, which was also identified as a crucial factor for successful reorganisation (Mayr and Mitter, 2015). This high level of commitment of the entrepreneur can manifest itself also in financial contributions from the owners, which appear as another influential variable in our study. However, less than half of the firms 
investigated were able to rely on such financial contributions. Hence, our study points to a reluctance or inability of many SME entrepreneurs to provide additional funds in a crisis situation. This is corroborated by research on SMEs' responses to an external crisis in the UK and New Zealand (Smallbone et al., 2012) that highlights that owner/manager commitment comes more in the form of working longer hours than financial contributions such as investment of personal savings or the sale of personal assets to compensate for poor business performance. In sum, based on our empirical results, a sound reorganisation plan paired with entrepreneurial discretion and commitment-along with the entrepreneur's capabilities and attitudes-are the most vital factors for successful reorganisation, while the entrepreneur's management and industry experience and the education do not play a decisive role.

Based on our empirical findings, we offer the following recommendations for corporate practice: During a company's financial crisis or in reorganisation, both creditors (especially banks) and consultants should attach importance to the entrepreneur's strong commitment to reorganisation and the planned measures. The reorganisation plan, which fully reflects these efforts, should therefore be subject to indepth analysis. To determine whether an entrepreneur is considered capable of successful reorganisation, the entrepreneur's special abilities should be examined. With regard to the success of reorganisation, dynamic-creative skills seem to be more important than administrative-executive skills. For entrepreneurs, these results mean that in addition to having the skills and competencies necessary for reorganisation, stakeholder support must also be gained. This can be achieved through owners' own financial contributions and a convincing reorganisation plan. Due to the high importance of the reorganisation plan, we recommend that universities and training institutions integrate the preparation of (business) plans even more strongly into their training and make future entrepreneurs aware of the multi-layered importance of a plan (confidence building, communication, management and control). As our findings show, especially in times of crisis or major restructurings the plan is a key success factor. For policymakers, this means that reorganisation plans must be included as a formal condition in court-proceedings. Consultants can compensate for deficits of entrepreneurs with restructuring-specific knowledge and ensure the success of the reorganisation.

A limitation of this paper is related to criticisms of upper echelons theory. Oppong (2014) argues that demographic-based studies have been quite successful at describing the relationship between manager characteristics and firm performance but unsuccessful at explaining and controlling this dependency. Consequently, Priem et al. (1999) suggested that studies should move beyond the current interest in demography into investigating the factors that those characteristics are constructed to proxy. We tried to do so by using different types of entrepreneurs with different mindsets. Another limitation refers to the applied model by Fröhlich and Pichler (1988). More comprehensive and detailed models can provide additional insights. Thus, researchers might analyse different types of entrepreneurs from an even more interdisciplinary perspective with the help of qualitative research on power distributions, psychographic variances, and the judgement differences among entrepreneurs. Future research might also address the relationship between dynamic-creative/risk-taking characteristics and planning skills. Another limitation lies in the sample characteristics of our study. We investigated a rather small dataset of Austrian bankruptcies. Hence, the generalisability of our findings and their transferability to other countries, in which bankruptcy laws differ, might be questioned. 


\section{References}

Aldrich, H.E. and Auster, E. (1986) 'Even dwarfs started small: liabilities of age and size and their strategic implications', Research in Organizational Behavior, Vol. 8, pp.165-198.

Alvarez, S.A. and Busenitz, L.W. (2001) 'The entrepreneurship of resource-based theory', Journal of Management, Vol. 27, No. 6, pp.755-775.

Analoui, F. and Karami, A. (2003) Strategic Management in Small and Medium Enterprises, Thomson Learning, London.

Armstrong, C.E. and Shimizu, K. (2007) 'A review of approaches to empirical research on the resource-based view of the firm', Journal of Management, Vol. 33, No. 6, pp.959-986.

Ayyagari, M., Beck, T. and Demirguc-Kunt, A. (2007) 'Small and medium enterprises across the globe', Small Business Economics, Vol. 29, No. 4, pp.415-434.

Barney, J.B. (1991) 'Firm resources and sustained competitive advantage', Journal of Management, Vol. 17, No. 1, pp.99-120.

Bates, T. (1990) 'Entrepreneur human capital inputs and small business longevity', The Review of Economics and Statistics, Vol. 72, No. 4, pp.551-559.

Boden, R.J. and Nucci, A.R. (2000) 'On the survival prospects of men's and women's new business ventures', Journal of Business Venturing, Vol. 15, No. 4, pp.347-362.

Bögenhold, D., Fink, M. and Kraus, S. (2014) 'Integrative entrepreneurship research - bridging the gap between sociological and economic perspectives', International Journal of Entrepreneurial Venturing, Vol. 6, No. 2, pp.118-139.

Brandstätter, H. (2011) 'Personality aspects of entrepreneurship: a look at five meta-analyses', Personality and Individual Differences, Vol. 51, No. 3, pp.222-230.

Brüderl, J., Preisendörfer, P. and Ziegler, R. (1992) 'Survival chances of newly founded business organizations', American Sociological Review, Vol. 57, No. 2, pp.227-242.

Burns, P. (1996) Entrepreneurship and Small Business, Palgrave, London.

Carpenter, M.A., Geletkanycz, M.A. and Sanders, W.G. (2004) 'Upper echelons research revisited: antecedents, elements, and consequences of top management team composition', Journal of Management, Vol. 30, No. 6, pp.749-778.

Carter, R. and Van Auken, H. (2006) 'Small firm bankruptcy', Journal of Small Business Management, Vol. 44, No. 4, pp.493-512.

Chen, G. and Hambrick, D.C. (2012) 'CEO replacement in turnaround situations: executive (Mis)F' It and Its Performance Implications', Organization Science, Vol. 23, No. 1, pp.225-243.

Chitnomrath, T., Evans, R. and Christopher, T. (2011) 'Corporate governance and post-bankruptcy reorganisation performance', Asian Review of Accounting, Vol. 19, No. 1, pp.50-67.

Chowdhury, F., Terjesen, S. and Audretsch, D. (2015) 'Varieties of entrepreneurship: institutional drivers across entrepreneurial activity and country', European Journal of Law and Economics, Vol. 40, No. 1, pp.121-148.

Cook, G.A., Pandit, N.R. and Milman, D. (2012) 'A resource-based analysis of bankruptcy law, SMEs and corporate recovery', International Small Business Journal, Vol. 30, No. 3, pp.275-293.

Cooper, A.C., Gimeno-Gascon, F.J. and Woo, C.Y. (1994) 'Initial human and financial capital as predictors of new venture performance', Journal of Business Venturing, Vol. 9, No. 5, pp.371-395.

Cucculelli, M. and Peruzzi, V. (2020) 'Post-crisis firm survival, business model changes, and learning: evidence from the Italian manufacturing industry', Small Business Economics, Vol. 54, No. 2, pp.459-474.

D'Aveni, R.A. and MacMillan, I.C. (1990) 'Crisis and the content of managerial communications: a study of the focus of attention of top managers in surviving and failing firms', Administrative Science Quarterly, Vol. 35, No. 4, pp.634-657. 
Doern, R., Williams, N. and Vorley, T. (2019) 'Special issue on entrepreneurship and crises: business as usual? An introduction and review of the literature', Entrepreneurship and Regional Development, Vol. 31, Nos. 5-6, pp.400-412.

Fröhlich, E. and Pichler, J.H. (1988) Werte Und Typen Mittelständischer Unternehmer, Duncker, \& Humblot, Berlin.

Geroski, P.A., Mata, J. and Portugal, P. (2010) 'Founding conditions and the survival of new firms', Strategic Management Journal, Vol. 31, No. 5, pp.510-529.

Gilson, S. (1991) 'Managing default: some evidence on how firms choose between workouts and chapter 11', Journal of Applied Corporate Finance, Vol. 4, No. 2, pp.62-70.

Gilson, S. (2012) 'Coming through in a crisis: how chapter 11 and the debt restructuring industry are helping to revive the U.S. economy', Journal of Applied Corporate Finance, Vol. 24, No. 4, pp.23-35.

Haas, N. and Speckbacher, G. (2017) 'Everything under my control: CEO characteristics and the evaluation of middle manager performance in small and medium-sized firms', Schmalenbach Business Review, Vol. 18, No. 2, pp.109-128.

Hambrick, D.C. (2007) 'Upper echelons theory: an update', Academy of Management Review, Vol. 32, No. 2, pp.334-343.

Hambrick, D.C. and Mason, P.A. (1984) 'Upper echelons: the organization as a reflection of its top managers', The Academy of Management Review, Vol. 9, No. 2, pp.1993-1206.

Headd, B. (2003) 'Redefining business success: distinguishing between closure and failure', Small Business Economics, Vol. 21, No. 1, pp.51-61.

Helfat, C.E. and Peteraf, M.A. (2003) 'The dynamic resource-based view: capability lifecycles', Strategic Management Journal, Vol. 24, No. 10, pp.997-1010.

Herbane, B. (2010) 'Small business research: time for a crisis-based view', International Small Business Journal, Vol. 28, No. 1, pp.43-64.

Hsieh, L., Child, J., Narooz, R., Elbanna, S., Karmowska, J., Marinova, S., Puthusserry, P., Tsai, T. and Zhang, Y. (2019) 'A multidimensional perspective of SME internationalization speed: The influence of entrepreneurial characteristics', International Business Review, Vol. 28, No. 2, pp.268-283.

Keasey, K., Pindado, J. and Rodrigues, L. (2015) 'The determinants of the costs of financial distress in SMEs', International Small Business Journal, Vol. 33, No. 8, pp.862-881.

Kücher, A., Mayr, S., Mitter, C., Duller, C. and Feldbauer-Durstmüller, B. (2020) 'Firm age dynamics and causes of corporate bankruptcy: age dependent explanations for business failure', Review of Managerial Science, Vol. 8, No. 9, pp.633-661.

Kwee, Z., van den Bosch, F.A.J. and Volberda, H.W. (2011) 'The influence of top management team's corporate governance orientation on strategic renewal trajectories: a longitudinal analysis of Royal Dutch Shell plc, 1907-2004', Journal of Management Studies, Vol. 48, No. 5, pp.984-1014.

Laitinen, E.K. (2013) 'Financial and non-financial variables in predicting failure of small business reorganisation', International Journal of Accounting and Finance, Vol. 4, No. 1, pp.1-34.

Lee, D.Y. and Tsang, E.W.K. (2001) 'The effects of entrepreneurial personality, background and network activities on venture growth', Journal of Management Studies, Vol. 38, No. 4, pp.583-602.

Lim, D.S.K., Morse, E.A. and Yu, N. (2020) 'The impact of the global crisis on the growth of SMEs: a resource system perspective', International Small Business Journal, Vol. 38, No. 6, pp.492-503.

Lussier, R.N. and Corman, J. (1996) 'A business success vs. failure prediction model for entrepreneurs with 0-10 employees', Journal of Small Business Strategy, Vol. 7, No. 1, pp.21-35. 
Madrid-Guijarro, A., García-Pérez-de-Lema, D. and Van Auken, H. (2011) 'An analysis of nonfinancial factors associated with financial distress', Entrepreneurship and Regional Development, Vol. 23, Nos. 3-4, pp.159-186.

Mayr, S. and Mitter, C. (2015) 'Rising like a phoenix: from bankruptcy to market leader', Journal of Small Business and Entrepreneurship, Vol. 27, No. 6, pp.519-536.

Mayr, S., Duller, C. and Stumbauer, K. (2020a) 'House banks in out-of-court reorganization: evidence from Austria', The Journal of Entrepreneurial Finance, Vol. 22, No. 1, pp.1-26.

Mayr, S., Mitter, C. and Aichmayr, A. (2017) 'Corporate crisis and sustainable reorganization: evidence from bankrupt Austrian SMEs', Journal of Small Business Management, Vol. 54, No. 1, pp.108-127.

Mayr, S., Mitter, C., Kücher, A. and Duller, C. (2020b) 'Entrepreneur characteristics and differences in reasons for business failure: evidence from bankrupt Austrian SMEs', Journal of Small Business and Entrepreneurship, doi: 10.1080/08276331.2020.1786647.

Mellahi, K. and Wilkinson, A. (2004) 'Organizational failure: a critique of recent research and a proposed integrative framework', International Journal of Management Reviews 5, Vol. 6, No. 1, pp.21-41.

Michael, S.C. and Combs, J.G. (2008) 'Entrepreneurial failure: the case of franchisees*', Journal of Small Business Management, Vol. 46, No. 1, pp.73-90.

Muller, P., Robin, N., Jessie, W., Schroder, J., Braun, H., Becker, L.S., Farrenkopf, J., Francisco, A.R., Caboz, S., Ivanova, M., Lange, A., Lonkeu, O.K., Mühlschlegel, T.S., Pedersen, B., Privitera, M., Bormans, J., Bogen, E. and Cooney, T. (2019) Annual Report on European SMEs 2018/2019: Research and Development and Innovation by SMEs, Publications Office of the European Union, Luxembourg.

Ooghe, H. and de Prijcker, S. (2008) 'Failure processes and causes of company bankruptcy: a typology', Management Decision, Vol. 46, No. 2, pp.223-242.

Oppong, S. (2014) 'Upper echelons theory revisited: the need for a change from causal description to casual explanation', Management, Vol. 19, No. 2, pp.169-183.

Perry, S.C. (2001) 'The relationship between written business plans and the failure of small businesses in the US', Journal of Small Business Management, Vol. 39, No. 3, pp.201-208.

Pinkwart, A., Proksch, D., Schefczyk, M., Fiegler, T. and Ernst, C. (2015) 'Reasons for the failure of new technology-based firms: a longitudinal empirical study for Germany', Credit and Capital Markets - Kredit Und Kapital, Vol. 48, No. 4, pp.597-627.

Priem, R.L., Lyon, D.W. and Dess, G.G. (1999) 'Inherent limitations of demographic proxies in top management team heterogeneity research', Journal of Management, Vol. 25, No. 6, pp.935-953.

Riar, F.J., Bican, J.R. and Fischer, J. (2021) 'It wasn't me: entrepreneurial failure attribution and learning from failure', International Journal of Entrepreneurial Venturing, Vol. 13, No. 2, pp.113-136.

Schutjens, V.A. and Wever, E. (2000) 'Determinants of firm success', Papers in Regional Science, Vol. 79, No. 2, pp.135-159.

Schweizer, L. and Nienhaus, A. (2017) 'Corporate distress and turnaround: integrating the literature and directing future research', Business Research, Vol. 10, No. 1, pp.3-47.

Shane, S. and Venkataraman, S. (2000) The Promise of Entrepreneurship as a Field of Research. The Academy of Management Review, Vol. 25, No. 1, pp.217-226.

Smallbone, D., Deakins, D., Battisti, M. and Kitching, J. (2012) 'Small business responses to a major economic downturn: Empirical perspectives from New Zealand and the United Kingdom', International Small Business Journal, Vol. 30, No. 7, pp.754-777.

Succurro, M. (2012) 'Bankruptcy systems and economic performance across countries: some empirical evidence', European Journal of Law and Economics, Vol. 33, No. 1, pp.101-126.

Thornhill, S. and Amit, R. (2003) 'Learning from failure: bankruptcy, firm age and the resourcebased view’, Organization Science, Vol. 14, No. 5, pp.497-509. 
Trahms, C.A., Ndofor, H.A. and Sirmon, D.G. (2013) 'Organizational decline and turnaround', Journal of Management, Vol. 39, No. 5, pp.1277-1307.

Ucbasaran, D., Shepherd, D.A., Lockett, A. and Lyon, J. (2013) 'Life after business failure: the process and consequences of business failure for entrepreneurs', Journal of Management, Vol. 39, No. 1, pp.163-202.

Wang, G., Holmes, R.M., Oh, I-s. and Zhu, W. (2016) 'Do CEOs matter to firm strategic actions and firm performance? A meta-analytic investigation based on upper Echelons theory', Personnel Psychology, Vol. 69, No. 4, pp.775-862.

Wenzel, M. and Stanske, S., Lieberman, M.B. (2020) 'Strategic responses to crisis', Strategic Management Journal, doi: 10.1002/smj.3161.

Wernerfeldt, B. (1984) 'A resource-based view of the firm', Strategic Management Journal, Vol. 5, No. 2, pp.171-180. 